\title{
PEDAGOGICAL DOMAIN KNOWLEDGE FOR E-LEARNING
}

\author{
Duc-Long Le $^{(1)}$, Dinh-Thuc Nguyen ${ }^{(2)}$, An-Te Nguyen ${ }^{(2)}$, Van-Hao Tran ${ }^{(1)}$, Axel Hunger ${ }^{(3)}$ \\ (1) HCM city University of Pedagogy, Vietnam \\ (2) University of Science, VNU-HCM \\ (3) University of Duisburg-Essen, Germany \\ (Manuscript Received on September $21^{\text {th }}, 2010$, Manuscript Revised January $13^{\text {rd }}, 2011$ )
}

\begin{abstract}
In e-Learning, the face-to-face communication between instructors and learners are more limited than in traditional learning form. This causes difficulties for the teaching and learning process. Besides, the developing learning materials in the conventional way are also becoming less and less effective to learners. Therefore, building the productive learning contents is one of the main problems for e-Learning systems. In this paper, we deal with the development of learning contents and propose a mathematical model as pedagogical domain knowledge for e-Learning, called Knowledge Graph. Based on pedagogical and teaching analyses, Knowledge Graph is able to ensure logical and complete qualities for necessary standard knowledge of a given curriculum. Especially, the model is useful for undergraduate education in the developing countries such as Vietnam, where the training context needs strong content knowledge, and good procedures for the building of training programs and curricula. It can help educational administrators, pedagogical experts, and instructors to design high quality teaching and learning materials .
\end{abstract}

Keywords: e-Learning, prime idea (PI), necessary/hard-condition, Knowledge Graph (KG), SubKnowledge Graph (Sub-KG), e-Course

\section{INTRODUCTION}

E-Learning has been developing rigorously in a handful of formats and effective applications to serve the need for on-line education by instructors and learners. Through practical survey, researchers in education show that e-learning has brought plenty of benefits to training at college/university by helping instructors and students attain necessary skills of work in the $21^{\text {st }}$ century society [19][21][27]. With the specific applications, eLearning can enhance the relevance and effectiveness of education by enabling education to be more flexible in a way in which learning occurs: where, when, and how eLearning systems can link all educational activities together foe every individual or group to study and work, on-line or off-line, synchronously or asynchronously via computer networks, personal computers or other electronic devices.

Nevertheless, the problem of utilizing pedagogical methodologies into the system is not simple and still insufficient [23]. During the development process, e-Learning continually faces challenges from both of the

\section{Trang 14}


main actors, instructor and learner, e.g. how can system meet the requirements of the instructor and learner in order to serve effectively their on-line teaching and learning needs?

In an e-Learning system, the instructor plays the roles as an organizer, a manager as well as a supervisor in the learner's activities of a course by providing learning resources and supervising learning progress. Limited by indirect interaction with his $^{1}$ learners, the instructor expects the system to support two requirements as follows:

(I1) Learning contents are able to substitute the instructor himself in transmitting knowledge in way of almost the same as the teaching activities in classroom meeting, where he is considered as a director in all learner's activities.

(I2) Learning contents and activities are able to provide sufficient classroom interaction in way of almost the same as direct interaction among the instructor, the learners and the groups.

On the other hand, a learner in the eLearning system has to be an active actor. The term "active" emphasizes the need for selfmotivation of learner's participation in the system, and the system will be less effective if the learner is not active enough or is under unwanted pressure. The two requirements

${ }^{1}$ The feminine form is used in this paper for learners and the masculine form for instructors. below must be met so that the learner herself can definitely benefit from the system:

(L1) Learning contents have to be complete, logical and pedagogical; they also match demand and ability of learner.

(L2) Learning activities should interest the learner and stimulate her learning desire.

To meet the above requirements, there are two delicate problems to be addressed: the design of learning contents and the development of learning activities in the eLearning systems.

Talking about the learning content, the designing and building of programs, curricula, courses, and lectures are necessary questions in teaching process. They are also considered as key phases in the development of learning contents and materials in both traditional learning form and e-Learning. Additionally, strengthening and improving learning contents in an e-Learning system can help compensate the lack of face-to-face communication between the instructor and learners [8][9]. Clearly, if learning contents can replace the teaching role of instructor in the class meeting, then learning activities in the e-Learning system will be almost similar to the traditional way of learning. In this paper, we care about the development of learning contents and propose a mathematical model as the fundamental model of domain knowledge for e-Learning, called Knowledge Graph (abbr. $K G$ that we will keep throughout the paper), which is formed by a set of the smallest basic knowledge called prime idea and its close 
relationship (see in section 3). Based on pedagogical analyses and basic teaching principles, the proposed model is able to ensure required qualities of learning contents (in a given curriculum) for the purposes of deploying the learning activities in the eLearning system.

The $K G$ model is really suitable for the undergraduate education context and even other training forms (e.g. K-12 school, inservice training) for developing countries such as Vietnam [25], where educational systems should improve more and more training programs, curricula and infrastructures. This training context is a combination of traditional learning and e-Learning, simply known as Blended-Learning Environment [26], where eLearning system is considered as a learningsupporting system. From that, it needs to have enough strong knowledge base and necessary procedures to build training programs, curricula, on-line courses, including textbooks, lecture notes, and develop learning activities in the system. So, $K G$ is able to support the system developers, educational administrators, pedagogical experts in the development and deployment of an e-Learning system [4][7], including the instructors on duty who expects to design high-quality learning materials and on-line lectures.

The rest of this paper will cover four sections. In section 2, we present the logical foundation based on the analyses of pedagogical and teaching aspects to reach to the proposed model; section 3 shows the $K G$ model together with the mathematical definitions and propositions (see in 3.1), then 3.2 presents the steps to build $K G$ that is considered as a curriculum of a specific training program; Section 4 displays an application of $K G$ in e-Learning; and the conclusion is presented in section 5 .

\section{PEDAGOGICAL ANALYSES}

The teaching and learning process in the traditional learning environment (abbr. traditional teaching process) is exhibited through the interaction among three factors: instructor - learner - knowledge [5]. Particularly, instructor's teaching methods and learner's learning methods together with the knowledge required by a given curriculum will create well-organized learning activities so that the learners can acquire that knowledge.

In the traditional teaching process, the communication between the instructor and learners is direct and face-to-face. With the given teaching goals and the amount of required knowledge, the instructor must know what to teach in class and how to teach to suit the needs of different learners. The instructor's ability in this case is not completely clear and explicit. It will be shown through teaching and learning progress in class where he usually recognizes what is necessary to help his learners understand the knowledge. Thus, it is often called the pedagogical ability and experience of instructor (a.k.a. instructor's pedagogical method or teaching skill). And then, the learners will acquire the knowledge 
and promote the skills through their learning methods by following the instructor's guidance and studying the learning materials.

Generally speaking, the traditional teaching process can be displayed by a process with the pedagogical concepts. Firstly, the design of a specific curriculum is usually done by the academia committee (e.g. educational administrators and pedagogical experts) for each different targeted type of learners and particular training goals. For example, there are some differences between the goal of Maths for K-12 school and the goal of Computer Science field for undergraduate education. Each curriculum constitutes a set of courses with relevant properties such as course objectives, requirements, relation of courses (such as prerequisite course, parallel course and independence course), key contents (in checklists), total hours, etc. Then each instructor in charge of a course designs the detailed syllabus for each particular class. The detailed syllabus discusses all specific key contents, it also describes up to the finest granularity of learning topics and weekly schedule for every class. Together with the reference materials suggested by the academia committee, the instructor prepares the materials and related resources for the learners. From detailed course syllabus, the instructor establishes the standards and goals for the topics and reorganizes the standard knowledge into teaching knowledge. Teaching knowledge is transferred and communicated directly to the learners in the class in form of learning topics (or lessons). And we easily see that a topic is represented in two main parts: prime ideas of the topic and the instructor's presentations. The prime idea is necessary standard knowledge required to be understood and memorized by the learner, however she can meet some difficulties to learn it during her self-study activity if there is not any guidance from instructor. The instructor's presentation is an act of displaying to make clear core knowledge basing on the instructor's pedagogical ability. Therefore, the instructor himself often designs the topic and uses it during the face-to-face communication between him and learners in the classroom to help the learners acquire knowledge easily.

For example, with the course "Fundamental Programming with C", one of prime ideas in the topic "Operators and Expressions" is "Relational and logical operators" and its statement as "Relational and logical operators include $<$; $<=$; $>$; $>=$; ==; $!=$ and $\& \& ; \| "$. In teaching process, the instructor should explain and make clear this prime idea basing on his pedagogical experience and the practical context of classroom (learners' ability and background) through explaining the operators above, giving some examples about strange operators to learner, guiding some practical exercises, for example. All of these works are mainly the teaching knowledge through instructor's representations directly to learners.

In brief, the relationship between curriculum and prime ideas is exhibited 
through multiple intermediate components; however both are developed and composed by the academia committee. Clearly, the curriculum is at a general level and aims at training goals whereas prime ideas are at detailed level and aim toward the most fundamental domain knowledge. As soon as the learners assimilate all prime ideas, they will have the overall necessary knowledge and be able to meet the required training goals.

Now let's consider the perspectives of instructors and learners. For the instructors, the set of prime ideas is complete knowledge and the most condensed content of the topic to be transmitted to learners. Therefore, prime idea is considered as the core knowledge component that needs to get sufficient attention during curriculum design. If the set of prime ideas is devised plans to build carefully, the learners will surely meet the required training goals. In other words, prime idea is the specific representation of fundamental knowledge in a curriculum. This explains why the set of prime ideas is needed to build by the academia committee. Furthermore, the instructors also present the set of prime ideas as a learning script to teach, from that he needs to know which prime ideas are the starting or ending knowledge, or which a prime ideas is prerequisite knowledge for other ones, or which a prime idea is necessary knowledge to guide the learning process of another one among the prime ideas. Consequently, the relationship between prime ideas has formed an ordered sequence of the domain knowledge for each curriculum, and it should be also developed by the academia committee to ensure the qualities of logicality and completeness. For this reason, our model has been proposed basing on prime ideas and their relationship to organize domain knowledge and deploy for applications in e-education and distance training field.

In currently-used e-Learning systems, the learning materials (e.g. course contents, lecture notes and reference resources) have always been received high attention and developed by the research community. An interesting thing is that the success of e-learning has long associated with the use of instructional design models in an early literature [22]. Indeed, thanks to instructional design, e-learning applications attain the connection between designing learning materials based on teaching theory with choosing and using technology effectively. However, previous researches in the field of instructional design almost have not either recognized the relationship between instructional design models and content knowledge, or they also did not concerned about the influences of pedagogical value in designing content knowledge, and vice versa. With the employment of more and more instructional designers for e-learning applications creates effective pedagogical strategies, commonly where the instructional designers are employed as pedagogical experts and not as content experts, or the practical educators - teachers/instructors - are content experts but not pedagogical experts. Clearly, 
the result will be a "gap" between learning content and pedagogical value of the strategy. The issue raises the need for the combination between building content knowledge with engaging pedagogical value to guarantee the two qualities: "effectivity" and "learning attraction" [11]. Rather, instructional design has focus on measuring the degree of using a set of teaching activities (i.e. lesson plans) for those deploying the teaching-learning system, under an assumption that these activities are effective, regardless of what topics learn, and how instructor's teaching skills transfer content knowledge to learners. There is no clue to reveal why researches in this area has not exploited the impact of essential pedagogical principles for instructional design, although some research in higher education has discovered the importance of instructor's pedagogical ability and experience in transferring content and ensuring the effectiveness of learning activities $[1][2][6][18][24]$. Moreover, there is not any recent work on a model to represent domain knowledge with the pedagogical analysis and teaching theories under perspectives of different users, such as educational administrators, pedagogical experts, instructors and learners, especially learners with their individual characteristics [20].

Focusing on building content knowledge for e-learning applications to ensure two qualities that analyzed above, the main question of our studies: "what is way to organize a content knowledge to meet pedagogical values as completeness and logicality that are represented for the value effectivity, and engaging learner into learning environment that is represented for the value learning attraction?" These pedagogical principles can be represented the instructor's role in transferring content knowledge to learners in class meeting. Then, hopefully when content knowledge is exploited in elearning applications, the limitation of lacking face-to-face communication is reduced (as presented in section 1). Briefly, it is necessary to build a model of domain knowledge that can support actively for the learning activities in eLearning systems [3]. Then, proposed Knowledge Graph [13][13][17] is mainly such a model and it is able to provide core knowledge of adaptive resources and services for instructor and learner, especially learner in self-study activities, in which the key idea of Knowledge Graph model refers to the engaging "pedagogical values" into the process of designing and building content knowledge. In the next sections, we further describe Knowledge Graph and its components.

\section{KNOWLEDGE GRAPH $(K G)$ MODEL}

In this section, we display two main parts, the first is the concepts of basic components built in $K G$, and the second is the procedure of building $K G$ as a specific curriculum.

\subsection{Definitions and propositions}

Definition 1. Prime-idea, also called PI for short, is the smallest knowledge unit about a 
specific technical topic and is explained in a short transparent paragraph.

We use the notation $\rho$, which is kept throughout the paper to express $P I$ in the next definitions and propositions.
Figure 1 illustrates generic structure for two particular PI's of course Fundamental Programming with $C$, including its components as ID, label, statement and category.

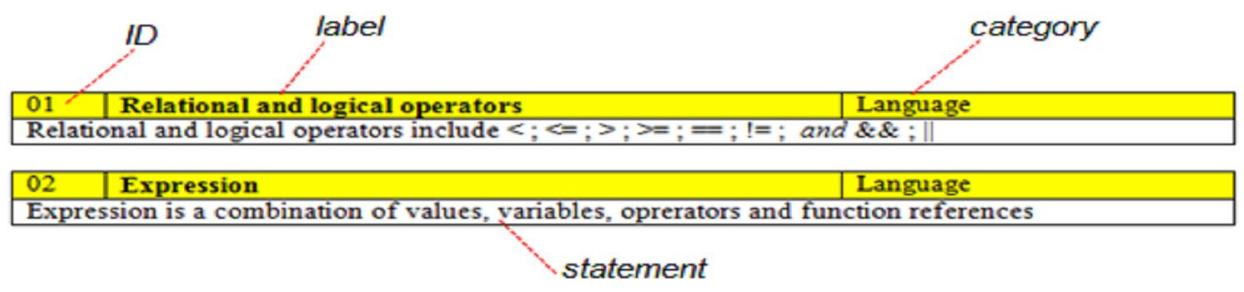

Figure 1. Example for PI and its components

We note two important properties of $P I$ as follows.

- Indivisibility. By its definition, PI is the smallest and indivisible knowledge unit. For example, supposed that $\rho$ is a given $P I$, if $\rho$ could be subdivided into two smaller units $\rho_{l}$ and $\rho_{2}$, then $\rho$ is not the smallest unit, and hence it is not a PI. Instead, $\rho_{1}, \rho_{2}$ could be PI's.

- Clarity. The statement of prime idea must have a single meaning (that means all learners must have exactly the same way of understanding the paragraph).

Definition 2. Hard-condition

(1) Let $\rho_{j}$ and $\rho_{k}$ be two different PI's, $\rho_{j}$ is called prerequisite knowledge of $\rho_{k}$ if and only if $\rho_{j}$ is required knowledge that must be understood before $\rho_{k}$ is learned (that means learner wants to understand $\rho_{k}$, then she must know $\rho_{j}$ in advance).
(2) Let $P=\{\rho\}_{i},(i=1, n)$ be a set of PI's. $P$ is called hard-condition of $\rho_{k}$, if and only if for each $\rho_{j}$ of $P(j \neq k)$, then $\rho_{j}$ is prerequisite knowledge of $\rho_{k}$

By the Definition 2, we see that hard-condition has two important properties:

- Mandatory. Hard-condition of $\rho_{k}$ is the mandatory knowledge prior to learning $\rho_{k}$. Therefore, the learner must have either acquired $\rho_{j}$ (hard-condition of $\rho_{k}$ ) or been prepared by the instructor in learning process.

- Prerequisite. If $\rho_{j}$ is the hard-condition of $\rho_{k}$, then the $\rho_{j}$ is immediately prior to the knowledge being learned $\rho_{k}$

Definition 3. Necessary-condition

Let $\rho_{j}$ and $\rho_{k}$ be the different PI's, $\rho_{j}$ is called necessary-condition of $\rho_{k}$, if and only if there is exactly one ordered sequence of PI's: $\rho_{l}, \rho_{2}, \ldots, \rho_{m}(m>2)$ such that $\rho_{j}=\rho_{l} ; \rho_{n}$ is the

\section{Trang 20}


hard-condition of $\rho_{n+1}(n=1, \ldots, m-1)$; and $\rho_{m}$ $=\rho_{k}$

Figure 2 illustrates concepts of hardcondition, necessary-condition, and an example of the relationship between PI's as $\rho_{4}$ is hardcondition of $\rho_{5} ; \rho_{1}$ or $\rho_{2}$ is necessary-condition of $\rho_{5} ; \rho_{3}$ and $\rho_{5}$ are independent of each other.

Definition 4. Relationship between two PI's

Give $\rho_{j}$ and $\rho_{k}$ are two PI's. There is exactly one and only one of the following relationships such that
(1) This $P I$ is hard-condition of the other onê. For instance, $\rho_{j}$ is hard-condition of $\rho_{k}$, a, and denoted as $\rho_{j}{ }_{\mathrm{h}} \rho_{k}$

(2) This $P I$ is necessary-condition of the other one. Fố instance, $\rho_{j}$ is necessarycondition of $\rho_{k}$, and denoted as $\rho_{j} \quad \rho_{k}$

(3) They are independent, if there is no necessary-condition relationship between them.
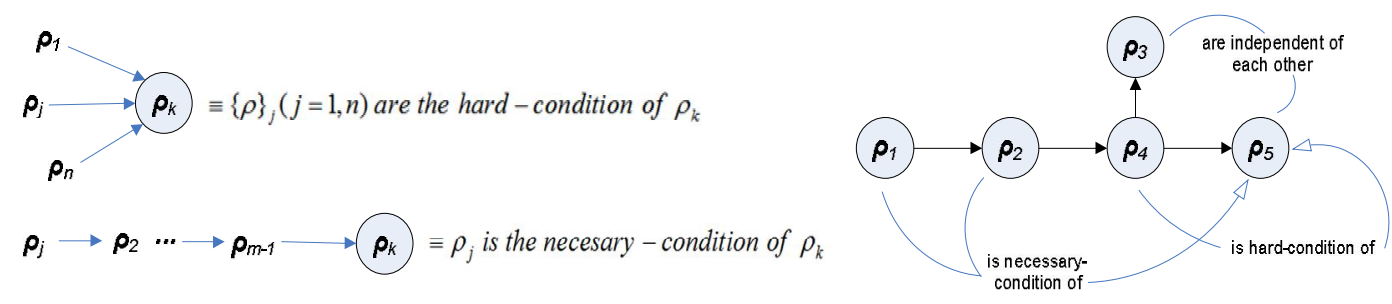

Figure 2. The relationship between $P I$ 's

Proposition 5. For all pair of different PI's: $\rho_{j}$ and $\rho_{k}$, they are independent or this one must be the necessary-condition of the other one.

Indeed,

(1) If $\rho_{j}$ and $\rho_{k}$ are hard-conditions of a prime-idea $\rho_{m}$, then $\rho_{j}$ and $\rho_{k}$ are independent

(2) Otherwise, suppose that $\rho_{j}$ is necessarycondition of $\rho_{m}$ and $\rho_{k}$ is hard-condition of $\rho_{m}$

In case, $\rho_{j}$ is necessary-condition of $\rho_{m}$, we have the following sub-cases:

- $\rho_{j}$ is also necessary-condition of $\rho_{k}$ by definition

- Otherwise, if $\rho_{j}$ is not necessary-condition of $\rho_{k}$ then $\exists \rho_{q}: \rho_{q}$ is hard-condition of $\rho_{m}$ and $\rho_{j}$ is necessary-condition of $\rho_{m}$. By (1) above, we have $\rho_{q}$ and $\rho_{k}$ are independent. Thus, $\rho_{j}$ and $\rho_{k}$ are also independent.

(3) Generally,

If $\rho_{j}$ is necessary-condition of $\rho_{m} \Rightarrow \exists \rho_{q}: \rho_{q}$ is hard-condition of $\rho_{m}$ and $\rho_{j}$ is necessarycondition of $\rho_{q}$

If $\rho_{k}$ is necessary-condition of $\rho_{m} \Rightarrow \exists \rho_{q}$, $: \rho_{q}$, is hard-condition of $\rho_{m}$ and $\rho_{k}$ is necessarycondition of $\rho_{q}$,

Consider the following two sub-cases: 
- If $\rho_{q}=\rho_{q}$, Then $\rho_{j}, \rho_{k}$ are necessaryconditions of $\rho_{q}$. Now, we just repeat (1), (2) and (3).

- Otherwise, we have $\rho_{j}, \rho_{k}$ are independent by definition.

Definition 6. Knowledge Graph - $K G$

Given a finite set of PI's: $\{\rho\}_{i},(i=1, n)$. Let $V=\{\rho\}_{i}$ be the yertex set, and $E=\left\{\left(\rho_{j}\right.\right.$, $\left.\left.\rho_{k}\right)\right\}_{j \neq k}$,

where $\left(\rho_{j}, \rho_{k}\right): \rho_{j} \quad{ }_{\mathrm{h}} \rho_{k}$ be the edge set. Then $K G=\langle V, E>$

Figure 3 illustrates some PI's of course Fundamental Programming with $C$.

Proposition 7. $K G$ is a concept map that has the following properties.

(1) $K G$ is a directed and acyclic graph (a.k.a. dag).

(2) $K G$ is minimum, i.e. $\square \rho_{j}, \rho_{k}: \rho_{j}<_{\mathrm{h}} \rho_{k}$ and $\rho_{j} \rho_{k}$. And, such a $K G$ is called the consistent Knowledge Graph.
Indeed,

(1.a) $K G=\langle V, E>$ is directed by Definition 6,

$\forall\left(\rho_{j}, \rho_{k}\right) \in E: \rho_{j} \kappa_{\mathrm{h}} \rho_{k}$

(1.b) $K G$ is acyclic. Let $\rho_{j}$ and $\rho_{k}$ be two arbitrary vertices of $K G$. Without loss of generality, assume $\rho_{j} \quad \rho_{k}$

And assume for contradiction that $K G$ is not acyclic, i.e. $\exists P=\rho_{1} \ldots \ldots \rho_{m} \rho_{m+1}$ such that $\rho_{1}=\rho_{k} ; \rho_{m+1}=\rho_{j} ;$ and $\rho_{1}<_{\mathrm{h}} \rho_{2}<_{\mathrm{h}} \ldots<_{\mathrm{h}} \rho_{m}$ $<_{\mathrm{h}} \rho_{m+1}$. Hence, $\rho_{k}<_{\mathrm{h}} \rho_{j}$. We also have $\rho_{j}<$ $\rho_{k}$, then $\rho_{k} \kappa_{\mathrm{h}} \rho_{j}$ and $\rho_{j}<\rho_{k}$. This does not agree with Definiton 4 . Therefore, we conclude that such a path $\mathrm{P}$ does not exist, so (1.b) is proved.

(2) $K G$ is minimum. Suppose $\exists \rho_{j}, \rho_{k}: \rho_{j} \leqslant \mathrm{~h} \rho_{k}$ and $\rho_{j} \rho_{k}$

By Definition 4, two PI's cannot have two different relationships simultaneously. Hence, it implies that (2) is proved.

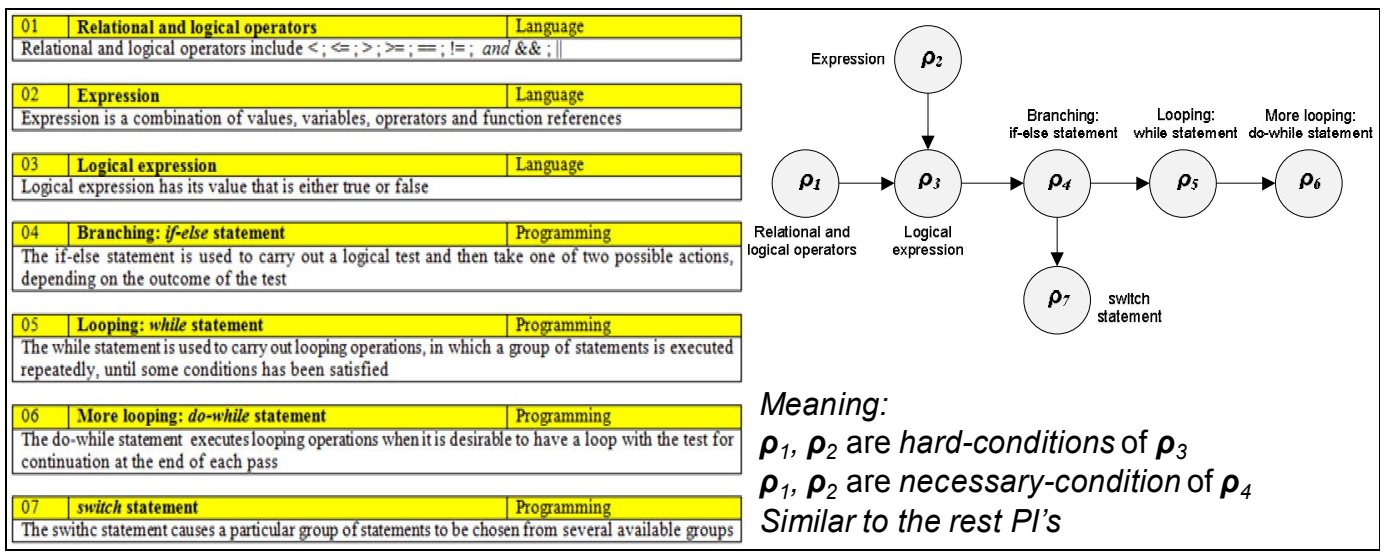

Figure 3. Some PI's of course Fundamental Programming with C 
Definition 8. Sub-Knowledge Graph - Sub$K G$

Given $K G=<V, E>$. Sub-KG=<V',E, $>$ is called a Sub-Knowledge Graph of $K G$ if and only if $V^{\prime} \subset V \wedge E^{\prime} \subset E$

In other words, $S u b-K G$ is the graph derived from $K G$, i.e. for a pair of vertices $\rho_{j}$ and $\rho_{k}$ in $S u b-K G$, we have $\left(\rho_{j}, \rho_{k}\right)$ is an edge in $S u b-K G$ if and only if $\left(\rho_{j}, \rho_{k}\right)$ is an edge in $K G$. By Definition 6, $K G$ itself is also a $s u b-K G$.

Definition 9. Started-PI and Ended-PI

Given a $S u b-K G$, let $\rho_{j}$, $\rho_{k}$ be the PI's of Sub-KG.

(1) If $\rho_{k}$ does not have any other $\rho_{j}$ to be its hard-condition, then $\rho_{k}$ is called Started-PI which represents the original or initial knowledge (of the current topic).

(2) If $\rho_{k}$ is not a hard-condition of any other $\rho_{j}$, then $\rho_{k}$ is called Ended-PI which represents the last or ending knowledge (of the current topic).

We see that the concept of Started-PI and Ended-PI is only relative depending on each specific context when the PI's are Started-PI's and Ended-PI's of a $K G$ or $S u b-K G$.

We have constructed the set of PI's as the fundamental knowledge of the training program and also defined the relationship between the PI's. Then the two components form a $K G$, and it can be able to represent curricula (with the set of different PI's) to meet the teaching goals of different training programs. Besides, $S u b-K G$ is a sub graph of $K G$ with the properties of $K G$ and it can represent a course, a topic or even a lecture depending on two main actors (e.g. instructors and learners) who use/deploy learning activities of instructional system. It could be seen easily that $K G$ is not a classical database but a knowledge base containing core knowledge of learning contents. Hence, $K G$ is the foundation to build specialized content knowledge for development of the teaching and learningsupported systems including e-Learning systems.

\subsection{Building $K G$ as a specific curriculum}

The set of PI's and curriculum have mutual relationship because PI's exhibit the training goals in detail at low level, and the curriculum in general at high level. In other words, there ought to be a mutual relationship between $K G$ and curriculum. Therefore, the proposed $K G$ above can represent the whole curriculum with the requirements of meeting the learning goals as well as representing necessary domain knowledge for design of Computer-Supported Collaborative Learning ( $a b b r$. CSCL) Systems [7] or Adaptive Educational Systems [4][19].

For example, to build a training program (of some learning branches) and its curriculum for the Vietnamese undergraduate education, firstly a scientific committee (e.g. professors, senior instructors, pedagogical experts) will determine the set of courses in curriculum basing on training goals. After that they build the general descriptions of each course with learning materials and necessary references. Then, the relationship of courses is established, and finally the curriculum is formed and sent to 
instructors in charge of a course for teaching and learning in the class. This subjective process is designed by the academia committee depending on the loose arguments of experts who are building the curriculum. Especially, it may be so difficult to ensure the consistency of a curriculum when the curriculum is built by different academia committees.

Additionally, the instructor in charge will have to prepare a practical syllabus and necessary knowledge of course by himself. Obviously, the amount of knowledge transmitted to learners is different from instructor to instructor. In case, the instructor does not have much experience in teaching (e.g. he is a student instructor or junior instructor), choosing what knowledge to transfer to his learners will become a more difficult task, making him be unable to completely achieve the training goal of course.

We propose a solution to this problem basing on $K G$, where the set of PI's is developed for each course and then the relationship and order between the courses are established from the relationship between the PI's within each course (see Figure 4).

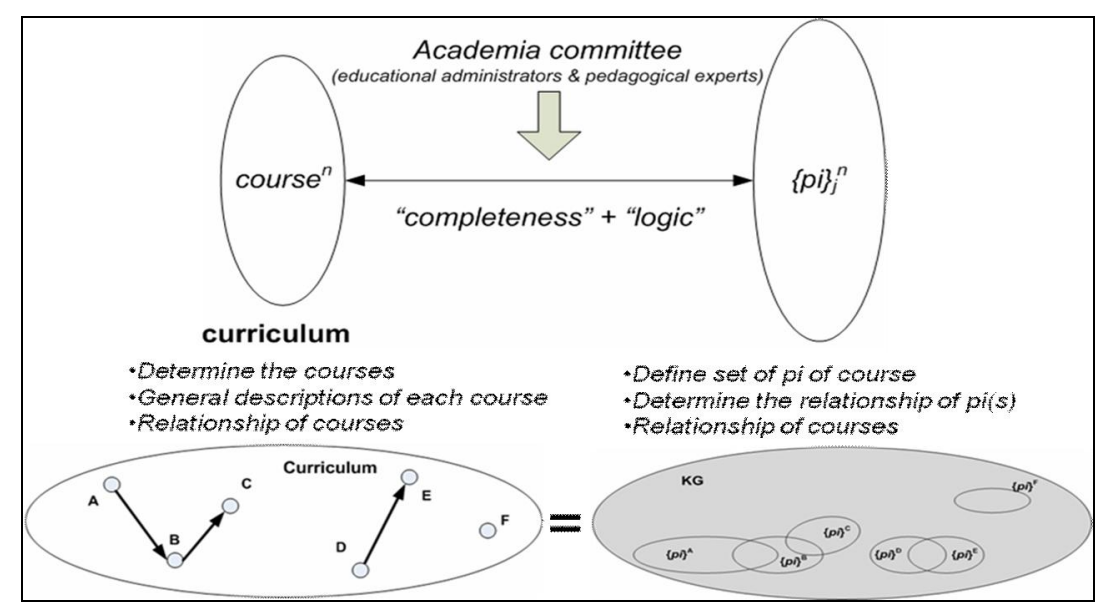

Figure 4. Relationship between $K G$ and curriculum

The proposed procedure shows a process to build $K G$ from the training goal of a specific curriculum. As a result, it aims at developing domain knowledge for the whole curriculum and proves that if $K G$ ensures logical and complete qualities of content knowledge, then instructional order of courses will also ensure these properties. In general, the process is built by an academia committee (including educational administrators, pedagogical experts, and course instructors) on manual. From that, when exploiting $K G$ in traditional learning environment, the curriculum based on $K G$ can assist the scientific committee (or academia committee) to re-evaluate the quality of different curricula or help the instructor in charge design his course easily. For e-Learning or on-line training, $K G$ will be pedagogical

\section{Trang 24}


domain knowledge for the systems and it is also considered as an expert model in adaptive educational system for providing suitable resources and services for each individual learner in form of "one to one instruction".

The solution details in the procedure that is printed in Figure 5.

\section{EXPLOITING $K G$ IN E-LEARNING}

During the teaching process of a course in traditional learning environment (as presented in Section 2), the instructor often bases on the syllabus of course to divide standard knowledge into various lessons. Each lesson is also split into many different topics so that they can be transmitted to learner with a sphere of knowledge in a given period of time. When every topic is presented to learner, the instructor always tends to make the learner understand the topic, grasp the basic knowledge, and apply this to practical situations such as assignments, exercises, case studies, and projects. Accordingly, a topic is designed and represented by the instructor to make clear necessary standard knowledge (i.e. PI) that he wants to transmit to learner basing on teaching technique and his pedagogical experiences. In e-Learning, the representation of each topic to satisfy all the demands above becomes more difficult because it lacks the direct interactions between the instructor and the learner, unlike in the traditional classroom meeting [9]. 


\begin{tabular}{|c|c|c|}
\hline \multicolumn{3}{|c|}{ Procedure building a specific curriculum basing on $K G$} \\
\hline \multicolumn{3}{|c|}{$\begin{array}{l}\text { procedure Building_a_curriculum } \\
\text { Input: training goals (adding national standards if we need) } \\
\text { Output: curriculum } \\
\text { Doer: educational administrators (1), pedagogical experts (2), course instructors (3) }\end{array}$} \\
\hline $\mathbf{N}^{\circ}$ & Steps & Doers \\
\hline 1 & $\begin{array}{l}\text { Determine the course of the curriculum. } \\
\text { 1.1. Select courses from the training goals } \\
\text { 1.2. Categorize the courses }\end{array}$ & $(1)+(2)$ \\
\hline 2 & $\begin{array}{l}\text { Construct the set }\{p l\}_{\mathrm{n}} \text { for each course } \\
\text { 2.1. Describe the pi's (as in Definition 1) } \\
\text { 2.2. Define the order of pi's and their relationship (as in Definition 2,3,4) }\end{array}$ & (3) \\
\hline 3 & $\begin{array}{l}\text { Revise and cohere the pi's } \\
\text { 3.1. Verify consistency in terminologies and contents of the pi's with } \\
\text { similar meaning/statement. } \\
\text { 3.2. Select and eliminate duplicate pi's }\end{array}$ & $(2)+(3)$ \\
\hline 4 & $\begin{array}{l}\text { Organize the courses in group to spot out relationships and knowledge } \\
\text { intersection. }\end{array}$ & (2) \\
\hline 5 & Determine the relationships between courses in the same group & (2) \\
\hline 6 & Determine the relationships between courses in different groups & (2) \\
\hline 7 & $\begin{array}{l}\text { Construct the knowledge graph for the curriculum (as in Definition } 6,8,9 \text { ) } \\
\text { 7.1. Draw the sub-KG for each course } \\
\text { 7.2. Draw the complete } K G \text { for the whole curriculum }\end{array}$ & $(1)+(2)$ \\
\hline 8 & Finalize and complete the curriculum according to the training goals. & $(1)+(2)$ \\
\hline
\end{tabular}

Figure 5. Procedure building KG as a curriculum

In this section, we present a process to build learning contents' representation of an on-line course; it is called e-Course for short [13][15]. The e-Course is designed primarily basing on $S u b-K G$ which is derived from $K G$ and considered as a pedagogical instance of the $S u b-K G$ to exploit $K G$ model from the user's aspect. The application focuses on two main actors in an adaptive e-Learning system, in which the instructor designs and builds $e$ Course in set of interacted lessons or lectures, and the learner uses e-Course in her learning activities in on-line or off-line form. It is also shown clearly that $S u b-K G$ is the fundamental knowledge of a course which can ensure logical and complete qualities of learning contents with the given goal. Additionally, $S u b-K G$ based on goal is able to develop in other learning activities such as evaluating the quality of course, reviewing learner's previousknowledge, recommending relevant knowledge for in-group discussion.

\section{Trang 26}


e-Course gathers together two factors, fundamental knowledge and instructor's pedagogical ability and teaching experience to transmit necessary knowledge to the learner and help her acquire the knowledge completely and easily, especially in the self-study activities via Internet. In other words, e-Course is the combination between core knowledge of course represented by $S u b-K G$ and a pedagogical interface designed by instructor. The core knowledge of the course or the "skeleton" of the course is $S u b-K G$ which is derived from $K G$ basing on goal. The pedagogical interface is also external component of the "skeleton" which is designed by the instructor to transfer knowledge effectively.

From that, $K G$ has been structuralized strong enough for developing and deploying for an Adaptive e-Learning system [16] which can adapt to characteristics of individual learner or leaner's group by learner profile (see Figure 6).

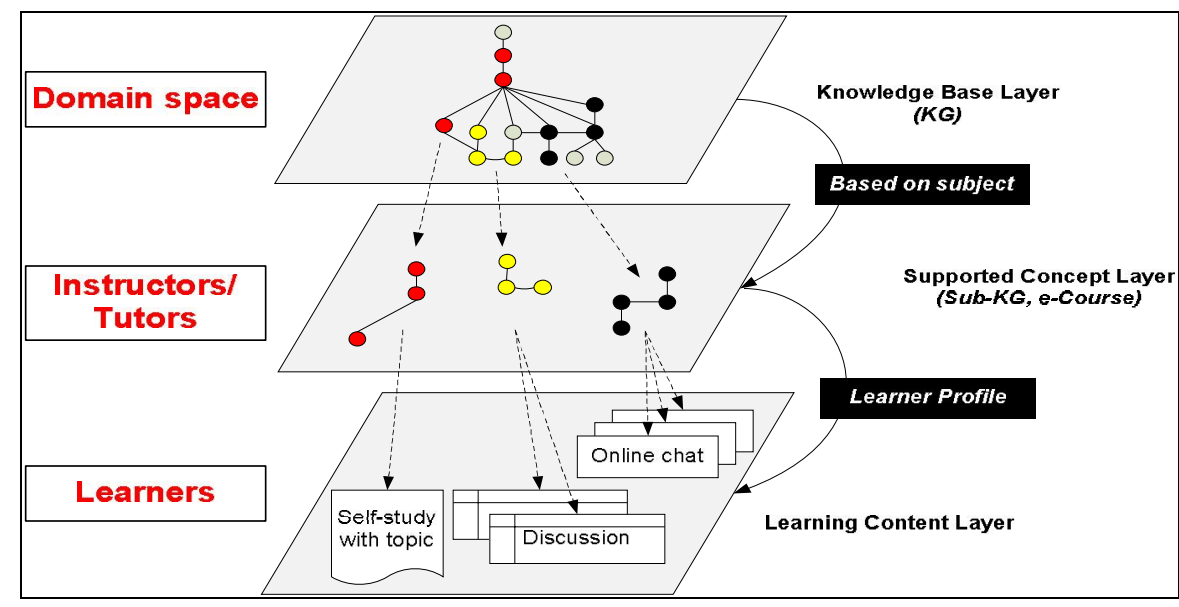

Figure 6. The layers of using $K G$ in Adaptive e-Learning System

In teaching and learning contexts of developing countries' undergraduate education now (such as Vietnam [25]), there are many disadvantages like as ineffective teaching methods, inadequate resources, lack of common or professional skills, weak capacity of network and infrastructures [10]. Then, the blended-learning form is a good way to support for instructor and learner in learning process in which Web-based course is an important computer-mediated technology and infrastructure, it consists of two parts: e-Course and e-Learning activities. Learner can be interactive actively with instructor or other learners in different styles; system will play a role of virtual tutor or virtual learner to participate these activities simultaneously $[13][15][15]$. 


\subsection{Building e-Course and an illustrated case study}

To build an e-Course, the procedure has two phases [17]
- Phase 1: Generating logical course (Sub$K G)$. It is presented in Section 3.2.

- Phase 2: Creating interface component of e-Course, namely building topics of the $e$-Course. (see in Figure 7)

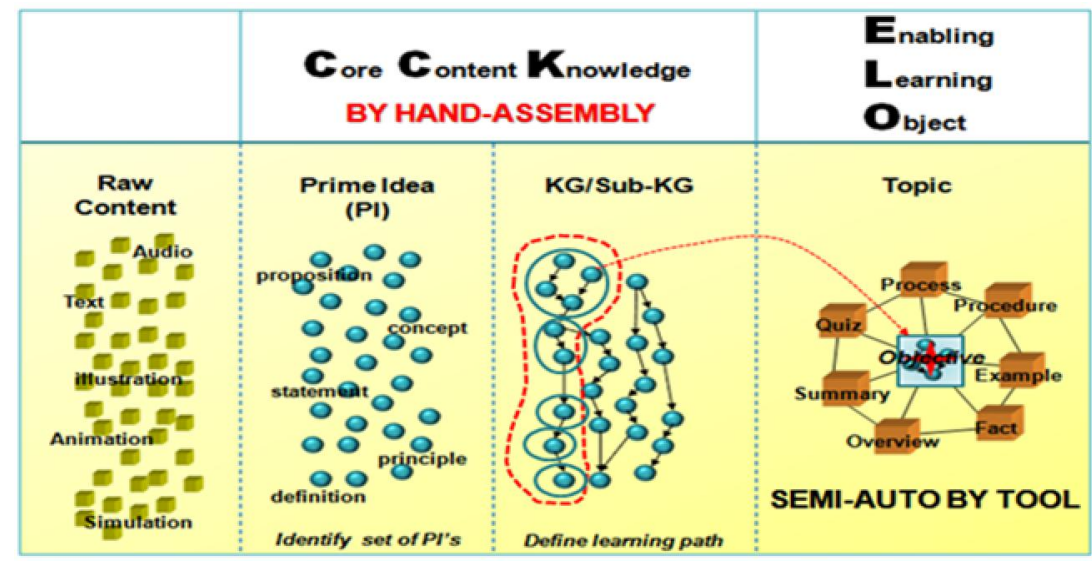

Figure 7. Building topic from Sub-KG and e-Course is collection of topics

Commonly, a topic includes:

- Core knowledge of the topic (with a specific objective/goal) is just PI's which need to be presented to learner. A topic can be structured from many PI's. External representation of the topic (through user interface of system) is the topic content to explain PI's within topic. It depends on design of each instructor.

-Topic can have various forms as concept/principle or process/operation; theory or exercise; easy or difficult; simple or complex. From that, the topic content will be edited and presented to suit a particular type of presentation (e.g. question, explanation, guiding in step-by-step, image, and diagram).
Different instructors can design a topic in many various forms but all of them must be built based on the same $S u b$ $K G$ of the course. It is proved that the qualities of completeness and logicality are still in each topic.

-A topic (that knowledge learns) is linked to another one (that previous knowledge learned or known) through using label of PI's.

-To develop an e-Course, the instructional designer should use authoring tools (e.g. Adobe Captivate, Articulate Studio, LectureMaker, Help \& Manual, and EXE) to product topics according to standard metadata (e.g. IEEE-LOM, SCORM, and AICC). 
Assumed that instructor Le want to build an on-line course "Programming with $C$ " in Bachelor's curriculum of Computer Science, then $L e$ needs to design learning materials for supporting his learners by IT equipments (e.g. personal computer) via Internet, and they can be lecture notes and related documentations in form an e-Course. With a given $K G$ of the academic curriculum and the objective of a specific course represented by the sets of Started-PI's and Ended-PI's, the system can generate a $\mathrm{S} u b-K G$, and clearly it is considered as core content knowledge of the course. From that, the instructor can use $S u b-K G$ to build $e$ Course's suitably with different learning contexts. In case of $L e$, there are three types of group learning including: type 1 has the individual characteristics of learners such as learning habit $=">2$ hours per day for internet", learning style = "active", background knowledge $=$ "good", frequency of self study = "permanent"; type 2 such as learning habit $=$ "<1 hour per day for internet", learning style = "passive", background knowledge = "inadequate", frequency of self study = "sometimes"; and type 3 is all of the rest. Therefore, $L e$ will design three e-Course's derived from $S u b-K G$ above, and Figure 8 presents a topic among the e-Course's.

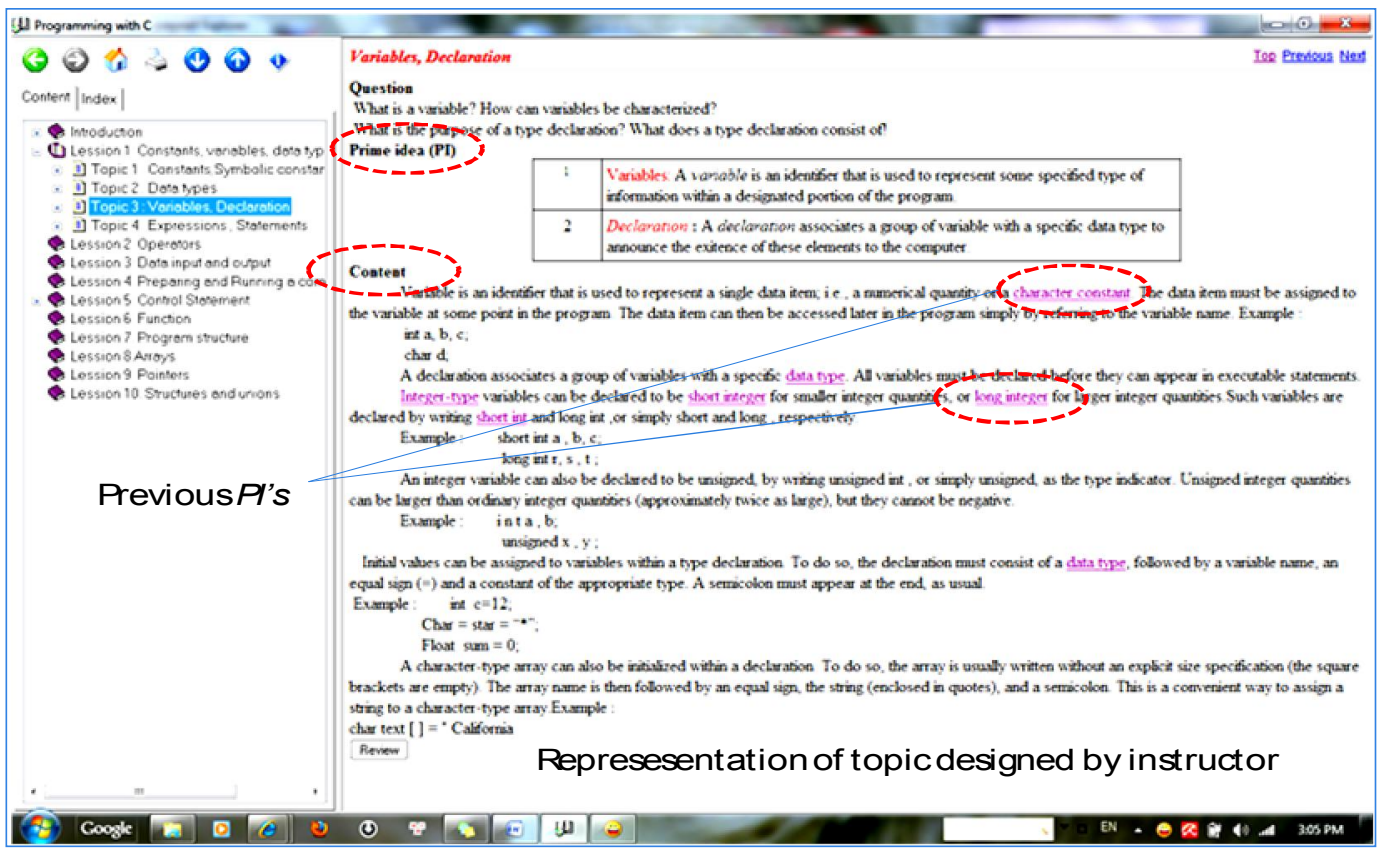

Figure 8. An inllustrated topic of e-Course by authoring tool Help\&Manual 5.x 


\subsection{Evaluating e-Course to determine the effectiveness of $K G$ model}

The article also presents an approach of the evaluating e-Course to determine if a training program has achieved its objectives and improved efficiency. It is based on Kirkpatrick's Evaluation Model [12].

Kirkpatrick's four levels of evaluation are:

- Level 4 - Results (long-term programmatic impact)

- Level 3 - Behavior (behavior change, adoption of best practice or new technology)

- Level 2 - Learning (knowledge gain, skills acquisition, attitude change)

- Level 1 - Participant Reaction (customer satisfaction)

Each level is important and has an impact on the next level. This is the sequence in which the evaluation of e-Course is planned, and the results should be determined in cooperation with participants at various levels. Commonly, surveys and/or interviews can be used in the evaluation.

To evaluate an e-Course consists of two phrases: formative evaluation and summative evaluation. At the phrase of formative evaluation, some few of practical instructors and learners randomly can be asked in interview or by means of a survey. At the second phrase, e-Course will be deployed in a specific virtual learning environment (i.e. VLE) with the real world contexts before performing a summative evaluation. Thus, our approach is more summative than formative and we have been used a method to the evaluation that can be applied directly to different Web-based courses.

The method has three evaluating instruments: a questionnaire survey, a system $\log$ file and its content analysis of learning process, and interviews with learners.

1. Questionnaire survey. It is designed with the purposes in mind: first to assess the acceptation and satisfaction of eCourse, second to gather information about learners that could help to identify some factors influencing the acceptation, and third, to collect information for bootstrapping the interviews with learners.

2. System log file and its content analysis. Log file can be stored datum about all of the hand-on activities of learner through system via Internet. It is able to determine and understand the learning process of learner such as when and which topics they viewed, what topics they interested in. Content analysis from $\log$ file is considered as an impersonal approach to review the acceptation and satisfaction of e-Course.

3. Individual interview with learners. These interviews are non-directive. Their purpose is to let the learner remember if they could or could not

\section{Trang 30}


complete their topics or tasks, and to explain why.

Now, our work has being implemented in courses such as Introduction to DB system, and Teaching Methods in Information Technology of HCMc University of Education, Vietnam based on a website online available: http://www.2learner.edu.vn/ACeLS/ (using LCMS Moodle), and the evaluation process has been begun of the course semester (from Sep, 2010 to Dec, 2011).

\section{CONCLUSIONS}

Established on the basic concepts of PI's and their relationship, $K G$ is an analytical model to represent the domain knowledge of applications in e-education and distance training field. The model is proposed in a mathematical form and it displays a fruitful combination between pedagogical theory and ICT technology for real instructional applications. We consider the model as a novel method to approach a solution to the developing of e-Learning systems, especially adaptive e-Learning system. Our analysis has shown that $K G$ is able to attain the qualities of logicality and completeness of the curriculum in general or the course in detail. And building the specific learning contents of course (with the concept of e-Course), which is combined set of core knowledge $(S u b-K G)$ and instructor's representations based on pedagogical ability and his experiences, has also represented pedagogical quality of $e$ Course.

Briefly, we can easily install and deploy an e-Learning system and improve the limited interactions among three key factors described in section 2 (i.e. instructor, learner and knowledge) through applying $K G$ model and $e$ Course. It aims at building the e-Learning system as a learning-supporting system and adapting the system to learning demands of individual learner or groups of learners. In our future researches, we continue to improve the $K G$ for developing the learning materials and enhancing the pedagogical quality of the domain knowledge's presentation (e.g. electures or e-textbook).

\title{
MỘT TRI THỨC LĨNH VỰC MANG TÍNH SU' PHẠM DÙNG CHO E-LEARNING
}

\author{
Lê Đức Long ${ }^{(1)}$, Nguyễn Đình Thúc ${ }^{(2)}$, Nguyễn An Tế ${ }^{(2)}$, Trần Văn Hạo ${ }^{(1)}$, Axel Hunger $^{(3)}$ \\ (1) ĐH Sư Phạm Tp.HCM \\ (2) Trường Đại học Khoa kọc Tự Nhiên, ĐHQG-HCM \\ (3) Đại học Duisburg-Essen, CHLB Đức
}


TÓM TÄT: Trong e-Learning, sự giao tiếp trục tiếp giũa người dạy và người học có nhiều hạn chế hơn so với hình thức đào tạo truyền thống, chính điều này thật sự khó khăn khi làm thế nào thoả mãn nhũng yêu cầu dạy và học đối với hai đối tuợng chinh này. Bên cạnh đó, việc phát triển các tài liệu học tập nói chung theo hình thức quen thuộc trước đây cũng càng lúc càng trở nên kém hiệu quả hơn đối với nguời học. Do vậy, xây dựng nội dung học tập có chất luợng là một trong nhũng vấn đề chính đối với nhũng hệ thống e-Learning. Trong bài báo này, chúng tôi đề cập đến việc phát triển nội dung học tập và đề xuất một mô hình toán học về lĩnh vục tri thức mang tính su phạm dùng cho e-Learning, được gọi mô hìn Đồ thị Tri thức (Knowledge Graph). Dựa trên nhũng phân tích su phạm và lí thuyết dạy học, Đồ thị Tri thức có thể đảm bảo các tính chất đầy đủ và hợp lí đối với luợng kiến thức chuẩn cần thiết của một chuoong trình đào tạo cho truớc. Đặc biệt là mô hình thật sư thich hợp cho việc khai thác trong môi truờng giáo dục đại học của các nuớc đang phát triển nhu ở Việt Nam, một nơi mà ngũ cảnh đào tạo cần có một nội dung tri thức đủ mạnh và nhũng thủ tụccần thiết để có thể xây dựng được các chuong trình đào tạo, kế hoạch chi tiết, nội dung khoá học và các hệ thống hỗ trọ học tập bởi nhũng nhà phát triển hệ thống, quản lí giáo dục, chuyên gia su phạm, kể cả nhũng nguời được phân công giảng dạy (giáo viên bộ môn) mong đọi để có thể thiết kế nhũng tài liệu học tập và bài giảng đạt chất lượng cao.

Tù̀ khoá: e-Learning, prime idea (PI), necessary/hard-condition, Knowledge Graph (KG), SubKnowledge Graph (Sub-KG), e-Course.

\section{REFERENCES}

[1] Ball, D.L., Mc Diarmid, G.W. The subject matter prepation of teachers. In W.R. Houston, M. Haberman \& J. Sikula (Eds.), Handbook of Research on Teacher Education, p.437-449, New York: Macmillan, (1990).

[2] Ball, D.L., Bass, H. Interweaving content and pedagogy in teaching and learning to teach: Knowing and using mathematics. In J. Boaler (Ed.), Multiple perspectives on the teaching and learning of mathematics (pp. 83-104). Westport, CT: Ablex, (2000).

[3] Brooks, C., Greer, J., Melis, E., Ullrich, C. Combining ITS and eLearning
Technologies: Opportunities and Challeneges. In Proceedings of the 8th International Conference on Intelligent Tutoring Systems (ITS), Taiwan, (2006).

[4] Brusilovsky, P. and Millan, E. The Adaptive Web, Methods and Strategies of Web Personalization. Springer, (2007).

[5] Filene, P. The joy of teaching: $A$ Practical Guide for New College Instructors. Published by the Uni of North Carolina Press, (2005).

[6] Grossman, P. The making of a teacher: Teacher knowledge and teacher education. New York: Teachers College Press, (1990).

[7] Henze, N. and Nejdl, W. Logically Characterizing Adaptive Educational

Trang 32 
Hypermedia Systems. In Proceedings of the International Workshop on Adaptive Hypermedia and Adaptive Web-based Systems (AH'03), Budapest, Ungarn, 15-29, (2003).

[8] Horton, W. Design and Writing Online Documentation: Hypermedia for SelfSupporting Products. $2^{\text {nd }}$ Edition. Published by Jon Wiley \& Sons, Inc, (1994).

[9] Horton, W. E-Learning by Design. Published by Pfeifer, an Imprint of Wiley, (2006).

[10] Jones, C., Holmfeld, L.D. and Lindström, B. A relational, indirect, meso-level approach to CSCL design in the next decade, ijCSCL - Springer, Vol.1- Issue 1,35-56, (2006).

[11] Kanuka, H. Instructional Design and eLearning: A Discussion of Pedagogical Content Knowledge as a Missing Construct, e-Journal of Instructional Science and Technology (e-JIST), Vol 9. No.2, (2006).

[12] Kirkpatrick, D.L. \& Kirkpatrick, J.D. I Evaluating Training Programs: The Four Levels, 3rd Ed., Berrett-Koehler Publishers, Inc., ISBN-10: 1-57675-3484, (2006).

[13] Le, D.-L. Toward a supporting system for e-Learning environment, IEEE International Conference on Research, Innovation and Vision for the Future
(RIVF). In Doctoral Symposium session, HCM city, Vietnam, 200-203, (2008).

[14] Le, D. -L., Bui, M.-T. -D., Nguyen, D.T., Hunger, A., Phan, C. -C. A model for Active-Collaborative eLearning. In Proceedings of Software and Groupware, Knowledge Techs and Open Source Solutions for E-learning Systems (SGK06), Hue, Vietnam, pp 96-102, (2006).

[15] Le D.-L., Tran, V.-H., Nguyen, D.-T. and Hunger, A. e-Course and its Applications in Blended-Learning Environment. In Proceedings of 2008 International conference on e-Learning, e-Business, Enterprise Information Systems, and eGovernment (EEE), Nevada, USA, 8995, (2008).

[16] Le, D.-L., Nguyen, A.-T., Nguyen, D.-T. and Hunger, A. Building Learner Profile in Adaptive e-Learning Systems. In Proceedings of the 4th International Conference on e-Learning (ICEL), Toronto, Canada, 294-304, (2009).

[17] Le, D.-L., Tran, V.-H., Nguyen, A.-T., Nguyen, D.-T. and Hunger, A. Applying Pedagogical Analyses to Create an Online Course for e Learning. In proceedings published by SpringerVerlag in Lecture Notes in AI as part of the LNCS/LNAI series. The 14th International Conference on KnowledgeBased and Intelligent Information \& Engineering Systems (KES 2010), Cardiff, Wales, UK,(2010). 
[18] Magnusson, S., Krajcik, J., Borko, H. Nature, Sources, and Development of Pedagogical Content Knowledge for Science Teaching. In J. Gess-Newsome and N.G. Lederman (Eds.), Examining Pedagogical Content Knownledge, p.95132, Netherlands: Kluwer Academic Publishers, (1999).

[19] Means, B. et al. Evaluation of EvidenceBased Practices in Online Learning: A Meta-Analysis and Review of Online Learning Studies, Final Report of US Department of Education, (2009).

[20] Mödritscher, F., Garcia-Barrios, V.-M., Gütl, C. The Past, the Present and the future of adaptive E-Learning. In Proceedings of the International Conference Interactive Computer Aided Learning (ICL), (2004).

[21] New Zealand Education Website, Ministry of Education, What is eLearning?, [on-line]. Available: http://www.minedu.govt.nz/NZEducatio n.aspx, (2009).

[22] Reiser, R. A. A history of instructional design and technology: Part II: A history of instructional design. Educational Technology, Research and Development, 49 (2), p.57-67, (2001).
[23] Schroeder, U. and Spanagel, C. Supporting the Active Learning Process, International JI on E-learning, Vol. 5(2), (2006).

[24] Shulman, L.S. Those who understand: Knowledge growth in teaching. Educational Researcher, 15(2), 4-14, (1986).

[25] Stephen, W. et al. Observations on undergraduate education in computer science, electrical engineering, and physics at select universities in Vietnam, A Report Presented to the Vietnam Education Foundation (VEF) by the Site Visit Teams of the National Academies of the United States, http://home.vef.gov/download/Report on Undergrad Educ E.pdf, (2006).

[26] Victoria, L.T. ICT in Education. Book 32 pages, UNDP Asia-Pacific Development Information Programme, www.apdip.net/publications/iespprimers/ ICTinEducation.pdf, (2003).

[27] Vilaseca, J. and Castillo, D. Economic efficiency of e-learning in higher education: An Industrial Approach, Intangible Capital, 4(3): 191-211- ISSN: 1697-9818, (2008).

\section{Trang 34}

